\title{
THE QUALITY ASSURANCE OF CAST AND WROUGHT AERO JET ENGINE COMPONENTS MADE FROM Ni-BASE SUPERALLOYS WITH USING OF QUANTITATIVE METALLOGRAPHY METHODS AND ALLOYS LIFETIME PREDICTION
}

doi: 10.2478/cqpi-2019-0030

Date of submission of the article to the Editor: 01/03/2019

Date of acceptance of the article by the Editor: 05/05/2019

\author{
Juraj Belan ${ }^{1}$ - orcid id: 0000-0002-2428-224X \\ Lenka Kuchariková1 - orcid id: 0000-0002-2688-1075 \\ Magdalena Mazur ${ }^{2}$ - orcid id: 0000-0003-3515-8302 \\ Eva Tillová ${ }^{-}$- orcid id: 0000-0002-1010-0713 \\ Patrícia Hanusová ${ }^{1}$ - orcid id: 0000-0002-5732-7990 \\ 1 University of Žilina, Slovakia \\ ${ }^{2}$ Czestochowa University of Technology, Poland
}

\begin{abstract}
The Ni-base superalloys are used in the aircraft industry for the production of aero engine most stressed parts, turbine blades or turbine discs. Quality of aero jet engine components has a significant influence on the overall lifetime of a jet engine as itself as well as the whole airplane. From this reason a dendrite arm spacing, grain size, morphology, number and value of $\gamma^{\prime}$ - phase are very important structural characteristics for blade or discs lifetime prediction. The methods of quantitative metallography are very often used for evaluation of structural characteristics mentioned above. The high-temperature effect on structural characteristics and application of quantitative methods evaluation are presented in this paper. The two different groups of Ni-base alloys have been used as experimental material: cast alloys ZhS6K and IN713LC, which are used for small turbine blades production and wrought alloys EI 698VD and EI 929, which are used for turbine disc production. Selected alloys have been evaluated in the starting stage and after applied heattreatment at $850^{\circ} \mathrm{C}$ for $24 \mathrm{hrs}$. This applied heat-treatment causes structural changes in all alloys groups. In cast alloy dendritic structure is degraded and gamma prime average size has grown what has a negative influence on turbine blade creep rupture life. Wrought alloys show partially grain boundary melting and grain size changed due to recrystallization what causes mechanical properties decreasing - ultimate tensile strength mainly.
\end{abstract}

Keywords: quality assurance, cast and wrought Ni-base superalloys, turbine blades, turbine discs, quantitative metallography 


\section{INTRODUCTION}

The aerospace industry is one of the leaders where innovative technologies and progressive construction materials are used. Speaking about progressive materials, the composites, aluminium, titanium, steel, and Ni-base superalloys are the most used sort of materials used for aeroplane construction - especially aero jet engines (Sjöberg, 2008; Okura, 2015).

The heat-proof and high-temperature Ni-base superalloys are high strength construction materials used in aero jet engine construction where high-temperature steels and titanium alloys do not fit with its mechanical properties. So, they are used for the most stressed parts working in a temperature range above $750^{\circ} \mathrm{C}$. There is developed a variety of Ni-base superalloys with special properties whose fulfil demands of designers (various loading limits and temperature range - according to its microstructure). The development of Ni-base superalloys was motivated by aero jet turbine engines and the necessity to work with higher temperatures in combustion or turbine section of a jet engine. Ni-base superalloys represent a quite wide group of complex alloys from a chemical composition point of view. Complicated alloying of base metallic $\gamma$ matrix with a high number of alloying elements (most of them in very small amounts) comes from empiric knowledge mainly and lot of experiments what had been made on this kind of alloys (Kracke, 2010; Akca, 2015; Huang et. al., 2016; Zhang et. al., 2018).

To express the relation between microstructure and mechanical properties, which are starting point for its optimal using and control it is necessary to quantify not only properties (those are often measured and expressed by number values) but also microstructure. The quantitative metallography evaluation includes methods for structural parameters quantification (evaluation via etalons, structural parameters measurements, automated image software analysis, and etc.) (Belan, 2012). Measurements in quantitative metallography have mainly statistical character. Into the fundamental quantitative metallography tasks belong:

- the grain size evaluation,

- secondary dendrite arm spacing so-called SDAS factor,

- evaluation of volume ratio of selected phases,

- evaluation of the number of selected phases,

- evaluation of particles size.

With relation, microstructure-mechanical properties not only in Ni-base superalloys deals recent research works done by (Oravcová et.al., 2017; Vaško, 2017; Zatkalíková et.al, 2017).

Depending on the type of Ni-base superalloy may grain size varies between small grains (ASTM 11-12) for the wrought type of alloys to large grain size (ASTM 1-0) for cast alloys. In the case of cast alloys rather than grain size, the SDAS factor is more reliable information. The Ni-base superalloys consist of the high volume of directionally segregated fine particles of $\gamma^{\prime}$-phase, which has an important influence on high-temperature properties. The consistent heat-treatment after casting, especially temperature and cooling rate have a significant influence on size and distribution of $\gamma^{\prime}$-phase, which is closely related to ultimate tensile strength (UTS) and creep rupture strength. The working temperature and loading of alloys have also a significant impact on morphology and volume of $\gamma^{\prime}$-phase changes.

The article deal with high-temperature influence on structural characteristics changes and application of selected quantitative metallography methods on wrought and casts Ni-base superalloys structure. 


\section{EXPERIMENTAL MATERIALS AND METHODS}

Four Ni-base alloys have been used as an experimental material; two cast superalloys ZhS6K and IN 713LC, two wrought EI 698VD and El 929. All alloys have been evaluated in the starting stage and after high-temperature loading $850^{\circ} \mathrm{C} / 24 \mathrm{hrs}$. The chemical composition in weight \% has been evaluated by spark spectrometer SpectroMAXx and is presented in Table 1.

Table 1

The chemical composition of superalloys; note: the content of $\mathrm{Ni}$ is a balance (wt.\%)

\begin{tabular}{|c|c|c|c|c|c|c|c|c|c|c|}
\hline Alloy & C & Co & $\mathrm{Nb}$ & $\mathrm{Ti}$ & $\mathrm{Cr}$ & Al & W & Mo & $\mathrm{Fe}$ & Mn \\
\hline IN 713LC & 0.047 & 0.06 & 1.86 & 0.67 & 12.6 & 6.12 & 0.08 & 4.43 & - & 0.02 \\
\hline ZhS6K & $\begin{array}{l}0.13 \\
- \\
0.2\end{array}$ & $\begin{array}{l}4.0 \\
- \\
5.5 \\
\end{array}$ & - & $\begin{array}{l}2.5 \\
- \\
3.2\end{array}$ & $\begin{array}{c}9.5 \\
- \\
12\end{array}$ & $\begin{array}{l}5.0 \\
- \\
6.0\end{array}$ & $\begin{array}{l}4.5 \\
- \\
5.5\end{array}$ & \begin{tabular}{|l|}
3.5 \\
- \\
4.8
\end{tabular} & 2.0 & 0.40 \\
\hline El 698VD & $\begin{array}{l}0.03 \\
- \\
0.07\end{array}$ & - & $\begin{array}{l}1.9 \\
- \\
2.2\end{array}$ & $\begin{array}{l}2.35 \\
- \\
2.75\end{array}$ & $\begin{array}{c}13 \\
- \\
16\end{array}$ & $\begin{array}{l}1.45 \\
- \\
1.8\end{array}$ & - & \begin{tabular}{|l|}
2.8 \\
- \\
3.2
\end{tabular} & 2.0 & 0.4 \\
\hline 29 & $\begin{array}{l}0.04 \\
- \\
0.1\end{array}$ & $\begin{array}{l}12 \\
- \\
16\end{array}$ & - & $\begin{array}{l}1.4 \\
- \\
2.0\end{array}$ & $\begin{array}{l}9 \\
- \\
12\end{array}$ & $\begin{array}{l}3.6 \\
- \\
4.5\end{array}$ & $\begin{array}{l}4.5 \\
- \\
6.5\end{array}$ & \begin{tabular}{|l|}
4.0 \\
- \\
6.0
\end{tabular} & $\max 5.0$ & 0.5 \\
\hline
\end{tabular}

Source: Own data

IN 713LC is a nickel-base casting alloy developed for applications requiring high strength at elevated temperatures. Its balanced composition provides a good combination of tensile and creep-rupture properties as a result of $\gamma^{\prime}$-phase strengthening enhanced by solid solution and grain-boundary strengthening. IN 713LC alloy performs a good castability. Castings are used in as-cast state, without heat treatment. Currently, this alloy is used widely, for example, for manufacturing of turbine wheels in turbochargers.

This alloy is used for the turbine rotor blade and whole cast small sized rotors with working temperature from 800 up to $1050^{\circ} \mathrm{C}$. The alloy is made in vacuum furnaces. The temperature of the liquid at casting in vacuum form $1500^{\circ} \mathrm{C} \div 1600^{\circ} \mathrm{C}$, depends on parts shape and amount. Cast ability of this alloy is very high with only $2 \%-2.5 \%$ shrinkage. Blades made of this alloy are also protected against hot corrosion with protective heat proof alitize layer, so there are able to work at temperatures up to $750^{\circ} \mathrm{C}$ for 500 flying hours.

The creep resistant wrought nickel base superalloy El 698 VD is suitable for the manufacturing of discs and shafts of aircraft engines and can be exposed to temperatures up to $760^{\circ} \mathrm{C}$.

Alloy El 929 is wrought superalloy used for working temperatures up to $950^{\circ} \mathrm{C}$. It has lowered $\mathrm{Cr}$ content and is alloyed with Co.

For structural characteristics, the quantitative metallography methods have been used, as fallow:

- The Saltykov rectangle method (Saltykov, 1958) for grain size evaluation has been used and ASTM E112-12 standard for grain size number determination.

- For dendrite microstructure evaluation of cast alloys the SDAS factor calculation was used (Hanumantha Rao et. al, 2010).

- A coherent testing grid with a various number of probes has been used for $\gamma^{\prime}$-phase evaluation; 9 square shape area probes were used for the number of $\gamma^{\prime}$-phase particles 
evaluation and 50 dot probes made from backslash crossing were used for the volume of $\gamma^{\prime}$-phase particles evaluation. In both cases, the SEM observation was used due to insufficient magnification on a light microscope.

\section{RESULTS AND DISCUSSION}

The structure of the initial state of the samples of wrought nickel superalloys EI 698VD is formed by grains of different size, carbides are excluded in globular form along grain boundaries, but also outside the grain boundaries, a large number of deforming twins can be observed on the section (Fig. $1 \mathrm{a}$ ). The structure of the El 929 sample is of more uniform grain size, carbides excluded at grain boundaries, and a large number of deformation twins can be seen on the cut as well (Fig. 1.b). The structure of the initial samples of cast nickel superalloys IN 713LC and ZhS6K is formed by a distinct dendritic structure and no grain boundaries are observable. Phase $\gamma^{\prime}$ has a finer distribution in dendritic axes and thicker in interdendritic spaces (Fig. 2.a, b).

a)

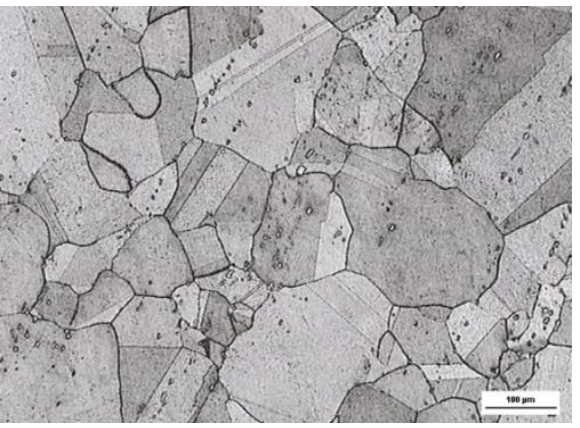

b)

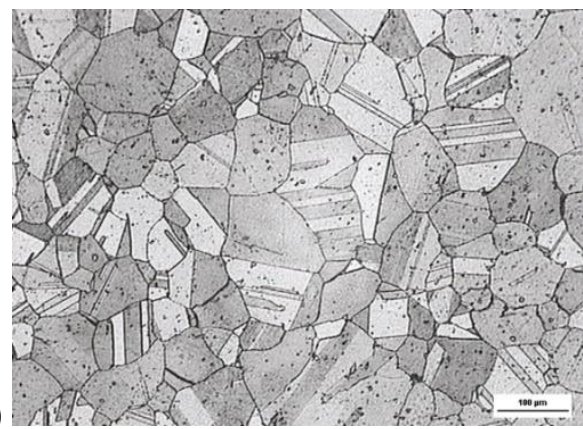

Fig. 1 Microstructures of wrought superalloys; starting stage: a) El 698VD, b) El 929, etch. MARBLE

a)

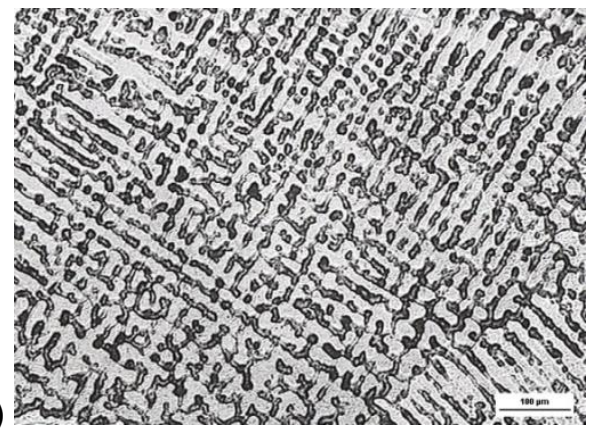

b)

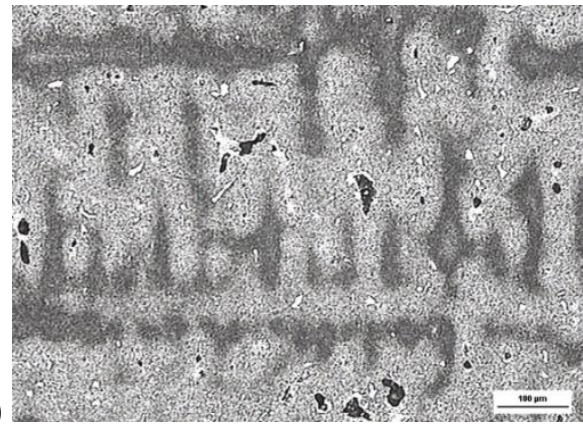

Fig. 2 Microstructures of cast superalloys; starting stage: a) IN 713LC, b) ZhS6K, etch. MARBLE

The structure of samples after $850^{\circ} \mathrm{C} / 24$ hours of wrought nickel superalloys El 698VD, consists of a variety of polyedric grains of the same size as in the initial state, but a higher number of deformation twins, the carbides began to form so-called carbide net (Fig. 3a). The structure of the sample El 929 is formed by uneven polyedric grains, with partial fusion of grain boundaries and the dissolution of secondary carbides at grain boundaries. There are also carbide particles excluded at the boundaries of the deformation twins (Fig. 3b), Tab. 2.

The structure of the samples of cast nickel superalloys IN 713LC and ZhS6K after $850^{\circ} \mathrm{C} / 24$ hours is a significant dendritic structure (Tab. 3) and the grain boundaries are observable, with a significant increase in the number of grains, and eutectics and carbides are excluded in interdendritic areas in different forms (Fig. 4a), (Fig. 4b). 
Table 2

Wrought Ni-base superalloy grain size evaluation according to Saltykov

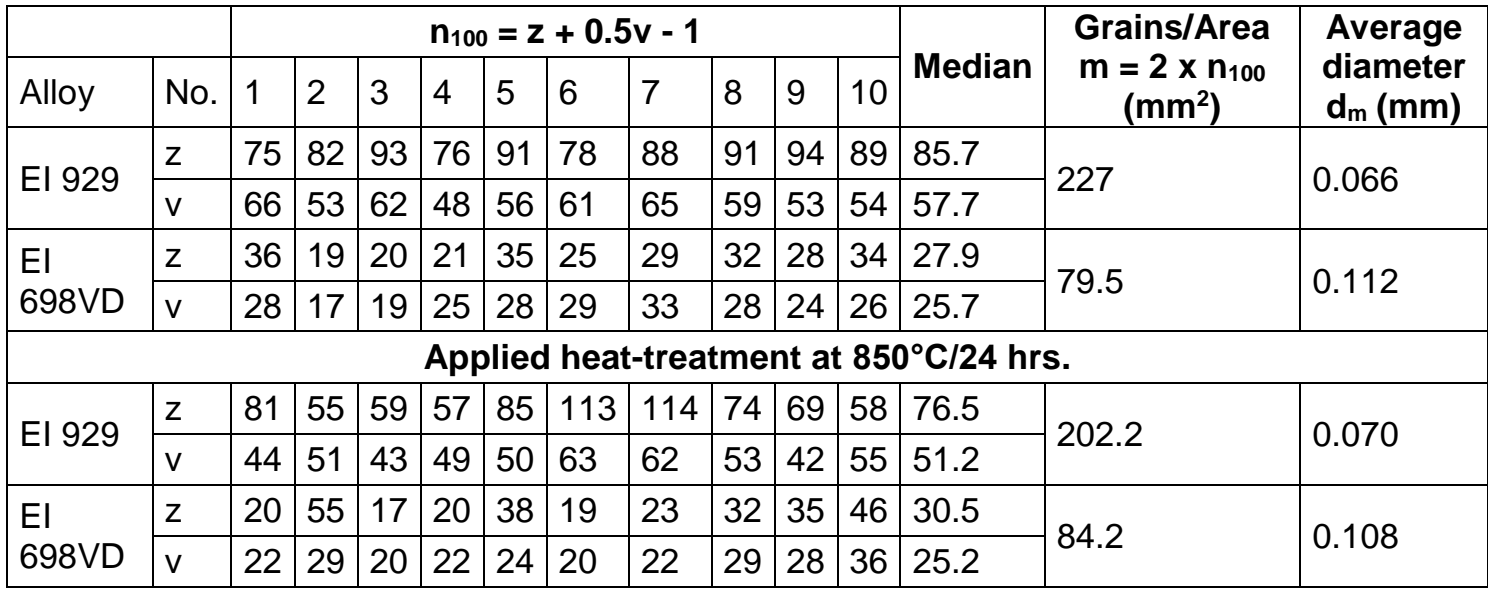

a)

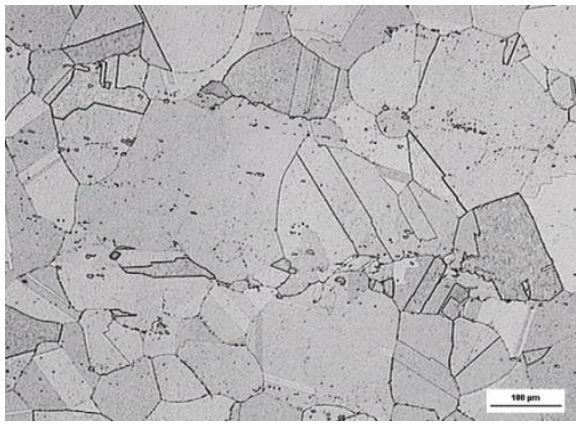

b)

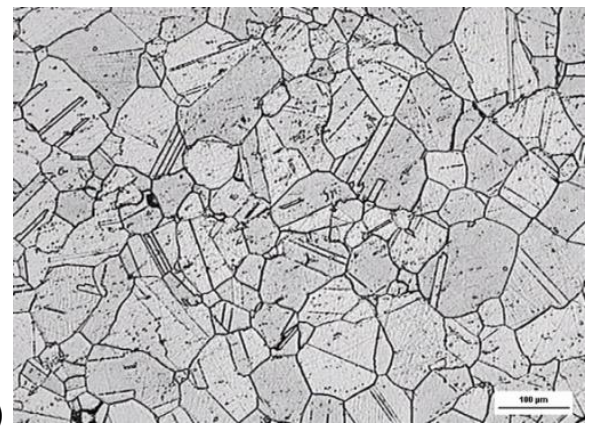

Fig. 3 Microstructures of wrought superalloys; after $850^{\circ} \mathrm{C} / 24$ hrs: a) El 698VD, b) El 929, etch. MARBLE

The effect of the thermal load at $850^{\circ} \mathrm{C} / 24 \mathrm{hrs}$ on wrought nickel superalloys were as follows: in the El 698VD alloy, the temperature and especially the 24 hour endurance at a given temperature caused partial melting of the grain boundaries as well as dissolution of the $\gamma^{\prime}$-phase to such an extent that it was not possible using coherent test grids. With the El 929 alloy, carbides dissolved due to temperature and holding time, and the $\gamma$-phase was evenly distributed, as well as the grain boundaries were melted, resulting in the re-crystallization of new grains during slow cooling at the initial grain boundaries. The effect of the thermal load at $850^{\circ} \mathrm{C} / 24 \mathrm{hrs}$ on cast nickel superalloys is as follows: for the IN 713LC alloy, the temperature, and in particular the 24-hour endurance at a given temperature, cause the carbides to become finer due to their dissolution, in addition to the pronounced (separated) grain boundaries, which are not observed at the starting stage. The influence of temperature and holding time at the temperature to the extent that the number of carbides increased not only at the boundaries but also outside the grain boundaries is the most pronounced for the ZhS6K alloy.

Results for volume and number of $\gamma^{\prime}$-phase (Fig. 5) measured with coherent testing grids are presented in Tab. 3 . 
a)

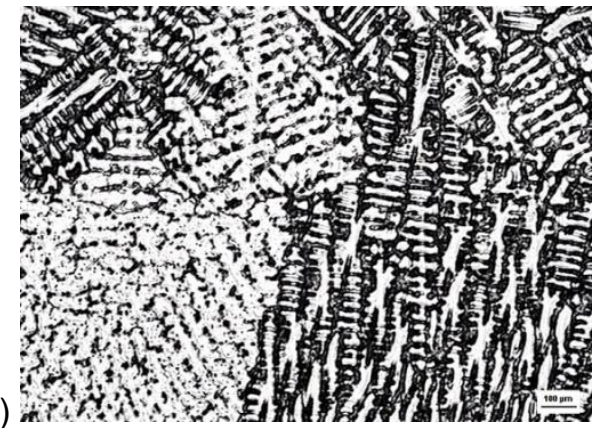

b) :

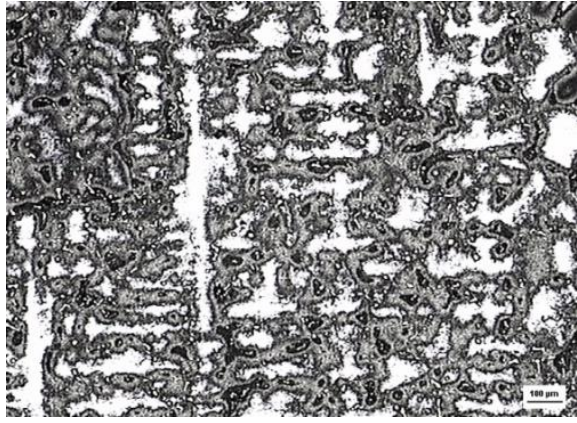

Fig. 4 Microstructures of cast superalloys; after $850^{\circ} \mathrm{C} / 24 \mathrm{hrs}$ : a) IN $713 \mathrm{LC}$, b) ZhS6K, etch. MARBLE

Table 3

Results for SDAS factor evaluation and coherent testing grid evaluation of $\gamma^{\prime}$-phase

\begin{tabular}{|c|c|c|c|c|c|}
\hline Alloy & $\begin{array}{l}\text { SDAS } \\
D(\mu \mathrm{m})\end{array}$ & $\begin{array}{c}\text { Number of } \\
\gamma^{\prime} \text {-phase / area } \\
N\left(\mu \mathrm{m}^{-2}\right)\end{array}$ & $\begin{array}{c}\text { Volume of } \\
\gamma^{\prime} \text {-phase } \\
\text { V (\%) }\end{array}$ & $\begin{array}{c}\text { Linear size of } \\
\gamma^{\prime} \text {-phase } \\
u(\mu \mathrm{m})\end{array}$ & $\begin{array}{c}\text { Area of } \\
\gamma^{\prime}-\text { phase } \\
a\left(\mu m^{2}\right)\end{array}$ \\
\hline & \multicolumn{5}{|c|}{ Starting stage } \\
\hline El 929 & - & 3.219 & 39.8 & 0.3516 & 0.1236 \\
\hline El 698VD & - & 3.078 & 45.8 & 0.3857 & 0.1487 \\
\hline IN 713LC & 36.4 & 0.635 & 53.4 & 0.9170 & 0.8409 \\
\hline \multirow[t]{2}{*}{ ZhS6K } & 90.1 & 2.184 & 36.8 & 0.4105 & 0.1684 \\
\hline & \multicolumn{5}{|c|}{ After $850^{\circ} \mathrm{C} / 24 \mathrm{hrs}$} \\
\hline El 929 & - & - & - & - & - \\
\hline El 698VD & - & - & - & - & - \\
\hline IN 713LC & 65.8 & 8.224 & 54.6 & 0.2576 & 0.0663 \\
\hline ZhS6K & 166.7 & 2.167 & 43.0 & 0.4454 & 0.1984 \\
\hline
\end{tabular}

After evaluating the individual experiments, it has been found that each nickel superalloy behaved differently after the thermal load. Wrought nickel superalloys, characterized by a fine-grained starting structure with pronounced deformation twins, were significantly degraded by the applied thermal load of $850^{\circ} \mathrm{C} / 24 \mathrm{hrs}$. The most pronounced degree of degradation occurred after 24 hours, where the grain boundary was partially melted with dissolving the secondary carbides at the grain boundaries for the El 929 alloy; for the El 698 VD alloy the total coherence of the $\gamma^{\prime}$-phase precipitate was lost and the undesired $\sigma$ phase was segregated too. These structural changes are also confirmed by the grain size values (Tab. 2) and the evaluation of the number and content (Tab. 3) of the $\gamma^{\prime}$-phase. The change in morphology and the amount of $\gamma^{\prime}$-phase precipitate is caused by re-precipitation of fine $\gamma^{\prime}$-phase particles and coarsening of the original phase. Cast nickel superalloys are characterized by significant dendritic segregation and a small number of grains. Similarly to wrought alloys, the temperature of $850^{\circ} \mathrm{C} / 24 \mathrm{hrs}$ affected the structure of the base material. The values indicating the distance of the secondary axes of the dendrite arms (Tab. 3) indicate diffusion processes and the redistribution of alloying elements in the $y$ matrix and the $Y^{\prime}$ precipitate - decreasing the chemical heterogeneity. The thermal load has affected the morphology and the amount of strengthening $Y^{\prime}$ phase.

Depending on the holding time at temperature, the number and content of the $\gamma^{\prime}$ phase first increase as a result of the re-precipitation of the fine $\gamma^{\prime}$ phase and dropped back to baseline at 24 hours. This phenomenon can be explained by the partial dissolution of carbides and 
diffusion of Al from the base material, resulting in a coarsening of fine $\mathrm{y}^{\prime}$ precipitate and a gradual loss of coherence.

a)

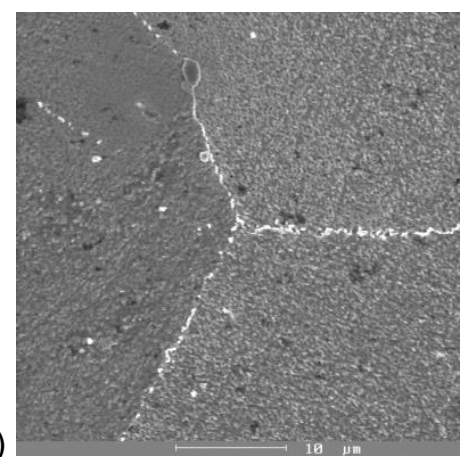

c)

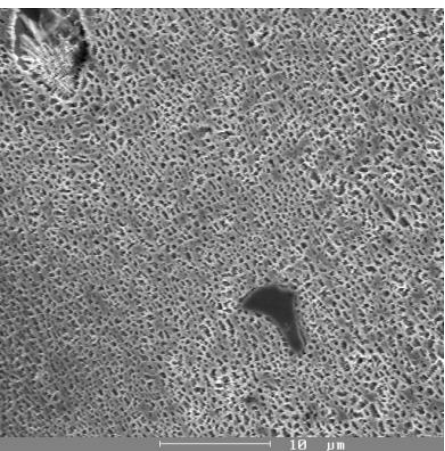

b)

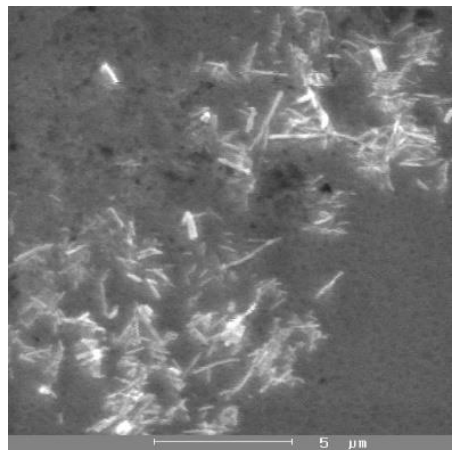

d)

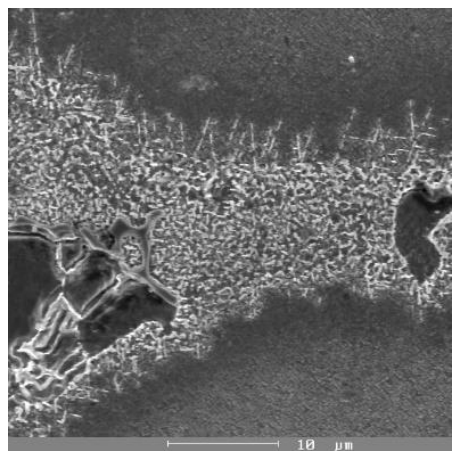

Fig. 5 Morphology of $\gamma^{\prime}$-phase, wrought alloy: a) El 698VD, starting stage, b) El 698VD after $850^{\circ} \mathrm{C} / 24 \mathrm{hrs}$, cast alloy c) ZhS6K, starting stage, d) ZhS6K after $850^{\circ} \mathrm{C} / 24 \mathrm{hrs}$, etch. MARBLE

In the case of the ZhS6K superalloy, an undesired $\sigma$ phase was eliminated in the structure after 24-hour endurance at the interface of interdendritic spaces. Exclusion of the $\sigma$ phase has a significant effect on mechanical properties, significantly reduces creep resistance and breaking strength (Marakumo et. al., 2004).

\section{CONCLUSION}

Wrought nickel superalloys EI 698VD and EI 929 and cast nickel superalloys IN 713LC and ZhS6K have been used as experimental material. Alloys structural parameters have been evaluated in the initial state and after thermal load at $850^{\circ} \mathrm{C} / 24 \mathrm{hrs}$ with using quantitative metallography methods:

- for the evaluation of grain size the Saltykov method, standard STN EN ISO 2624 (STN 42 0462) and ASTM E112-12 have been used;

- the fineness of the dendrites has been evaluated by the number of secondary arms (SDAS factor);

- the number and volume of $\gamma^{\prime}$-phase particles has been evaluated by means of a coherent test probe grid.

The results of the experimental work show that the temperature and especially the temperature endurance significantly influence the structural parameters. With wrought nickel superalloys, where the working temperature range is up to $600^{\circ} \mathrm{C}$, the grain boundaries and the $\mathrm{Y}^{\prime}$ precipitate have been completely degraded after 24 hours of endurance. For cast superalloys, with a working temperature of $750-1000^{\circ} \mathrm{C}$, the degradation processes is not so pronounced, but with longer holding times (24 hours) the hardening precipitate coarse, the carbides at the grain boundaries partially dissolve, and the 
undesired $\sigma$ phase is excluded for ZhS6K. All mentioned changes have a negative influence on mechanical properties, especially UTS and creep rupture strength.

\section{ACKNOWLEDGEMENTS}

The authors acknowledge the financial support of the projects KEGA No. 012ŽU-4/2019 and No. 049ŽU-4/2017.

\section{REFERENCES}

Akca, E., Gurse, I. A., 2015. A Review on Superalloys and IN718 Nickel-Based INCONEL Superalloy. Periodicals of Engineering and Natural Science, 3(1), 15-27.

Belan, J., 2012. Study of advanced materials for aircraft jet engines using quantitative metallography. In: R.K. Agarwal (Ed.), Recent Advances in Aircraft Technology, $1^{\text {st }}$ ed., Vol. 1, InTech, Rijeka, pp. 49-74.

Hanumantha Rao, D., Tagore, G.R.N., Ranga Janardhana, G., 2010. Evolution of artificial network (ANN) model for predicting secondary dendrite arm spacing in aluminium alloy casting. Journal of the Brazilian Society of Mechanical Sciences and Engineering, 32(3), 276-281, DOI: 10.1590/S1678-58782010000300011

Huang, X., Wang, L., Hu, Y., Guo, G., Salmon, D., Li, Y., Zhao, W., 2016. Fatigue Crack Propagation Behavior of Ni-Based Superalloys After Overloading at Elevated Temperatures. Progress in Natural Science: Materials International, 26(2), 197-203.

Kracke, A., 2010. Superalloys, the most successful alloy system of modern times-past, present and future. $7^{\text {th }}$ international symposium on Superalloy 718 and derivatives, 1350.

Marakumo, T., Kobayashi, T., Koizumi, Y., Harada, H., 2004. Creep behaviour of Ni-base single-crystal superalloys with various $\gamma^{\prime}$ volume fraction, Acta Materialia, 52, 3737-3744.

Okura, T., 2015. Materials for Aircraft Engines, ASEN 5063 Aircraft Propulsion Final Report, online: https://www.colorado.edu/faculty/.../materials-aircraft-engines

Oravcová, M., Palček, P., Chalupová, M., Uhríčik, M., 2017. Fracture mechanism differences created by fatigue and impact test. Materials Today - Proceedings, 4(5), 5921-5924.

Saltykov, S.A., 1958. Steremetricheskaya Metallograpfiya (Stereometric Metallography), 2nd revised and supplemented edition, Metallurgizdat, Moscow, 444p.

Sjöberg, G., 2008. Aircraft Engine Structure Materials. Volvo Aero Corporation, online: https://www.sto.nato.int/publications/.../EN-AVT-207-13.pdf

Vaško, A., 2017. Fatigue properties of nodular cast iron at low frequency cyclic loading. Archives of Metallurgy and Materials, 62(4), 2205-2210.

Zatkaliková, V., Oravcová, M., Palček, P., Markovičová, L., 2017. The effect of surface treatment on corrosion resistance of austenitic biomaterial. TRANSACTIONS OF FAMENA, 41(4), 25-34, DOI: 10.21278/TOF.41403

Zhang, H., Guan, Z.W., Wang, Q.Y., Liu, Y.J., Li, J.K., 2018. Effects of Stress Ratio and Microstructure on Fatigue Failure Behavior of Polycrystalline Nickel Superalloy. JMEPEG, 27, 2534-2544. 